\title{
BROTES DE FIEBRE AFTOSA EN EUROPA (1991-2005)
}

\author{
FOOT AND MOUTH DISEASE OUTBREAKS IN EUROPE (1991-2005)
}

\author{
Picado, A. ${ }^{12^{*}}$, S. Napp ${ }^{1 A} y$ J. Casal ${ }^{1 \mathrm{~B}}$ \\ ${ }^{1}$ Centre de Recerca en Sanitat Animal (CReSA). Campus UAB. 08193 Bellaterra,Barcelona. España. \\ E-mail: ASebastian.Napp@cresa.uab.cat; BJordi.Casal@uab.cat

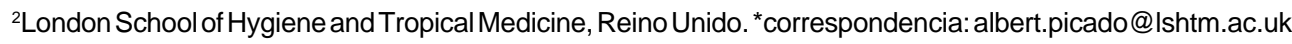

\section{Palabras clave adicionales}

Epidemia. Vías de entrada. Medidas de control.

\section{AdDitional KEYWORDS}

FMD. Control measures.

\section{RESUMEN}

La fiebre aftosa (FA) ha sido considerada durante muchos años como la enfermedad animal más importante debido a sus consecuencias sanitarias y económicas. Actualmente la enfermedad es endémica en varios países, especialmente de África y Asia. Por el contrario, Europa es una zona libre, si bien se siguen produciendo epidemias de forma esporádica. Europa erradicó la fiebre aftosa por medio de campañas de vacunación profiláctica que finalizaron en 1991. A partir de esa fecha la prevención de epidemias se basa en el control de las importaciones de animales y sus productos. Si bien las medidas establecidas han conseguido en general mantener fuera de Europa el virus de fiebre aftosa, varios países se vieron afectados por epidemias de esta enfermedad entre 1991 y 2005 . En este trabajo se revisan las epidemias más importantes agrupadas por el origen del brote: introducción de productos contaminados o de animales infectados. A pesar de las estrictas medidas de control establecidas en Europa, el riesgo de introducción del virus de la FA en Europa no es despreciable, como lo demuestran las distintas epidemias ocurridas en los últimos años.

\section{SUMMARY}

The foot and mouth disease (FMD) has, for a long time, been considered the most important animal disease. Nowadays this disease is endemic in several countries, especially in Africa and Asia. Europe, in contrast, is in general considered free of FMD even though it suffered from sporadic epidemics. Until 1991, when prophylactic vaccina- tion against FMD was forbidden, Europe eradicated the Foot and Mouth virus by extensive vaccination campaigns. Since 1991, the prevention became based on the control of animal and animal products importation. Even if those measures have been in general successful, several countries in Europe have suffered from FMD since 1991. This paper reviews the most important FMD outbreaks in Europe since 1991. The FMD epidemics were grouped by the origin of the outbreak: introduction of FMD virus contaminated products or infected animals. Even if the control measures are now more strict in Europe the recent FMD outbreaks show that the risk of introduction of FMD virus in Europe is not negligible.

\section{INTRODUCCIÓN}

La fiebre aftosa (FA) es una enfermedad infecciosa que afecta a los biungulados silvestres y domésticos (bovino, ovino, caprino y porcino) y está provocada por un virus de la familia Picornaviridae, género Aphtovirus. La enfermedad está ampliamente distribuida pero su presencia y presentación son variables según la zona. El periodo de incubación varía de 2 a 14 días dependiendo de las condiciones de infección y de la especie afectada (Radostits et al., 2000). Los signos clínicos de la FA son también variables y se caracterizan por la presencia de vesículas (aftas) y lesiones en las pezuñas, boca y ubres, y por provocar una alta 
mortalidad en jóvenes. Las lesiones y los signos clínicos suelen ser pronunciados en cerdo y bovino pero tienden a ser menos evidentes en ovino y caprino. El diagnóstico de la fiebre aftosa se basa en los signos clínicos y en pruebas de laboratorio como el ELISA para la detección de antígenos, el aislamiento del virus de FA o la RT-PCR (Ryan et al., 2008).

La FA tiene un impacto económico directo debido a la pérdida de productividad del rebaño (mortalidad de animales jóvenes y reducción de los índices productivos) y un gran impacto indirecto debido a su repercusión en el comercio y el turismo. Debido a su elevada infectividad es la primera enfermedad en la lista de la Office International des Epizooties (OIE), de modo que su presencia conlleva graves restricciones comerciales. La OIE define 6 categorías de regiones y países, en función de la presencia del virus y del uso de la vacunación profiláctica como medida de control. La pertenencia a una u otra categoría determina y limita la capacidad comercial con países o zonas que están en un nivel superior en la escala de la OIE (Código zoosanitario para los animales terrestres, Capítulo 2.2.10. www.oie.int).

El tipo de medidas de control usadas por los países depende de factores como las especies afectadas, la presencia previa de la enfermedad o las características del área afectada. La legislación internacional exis-

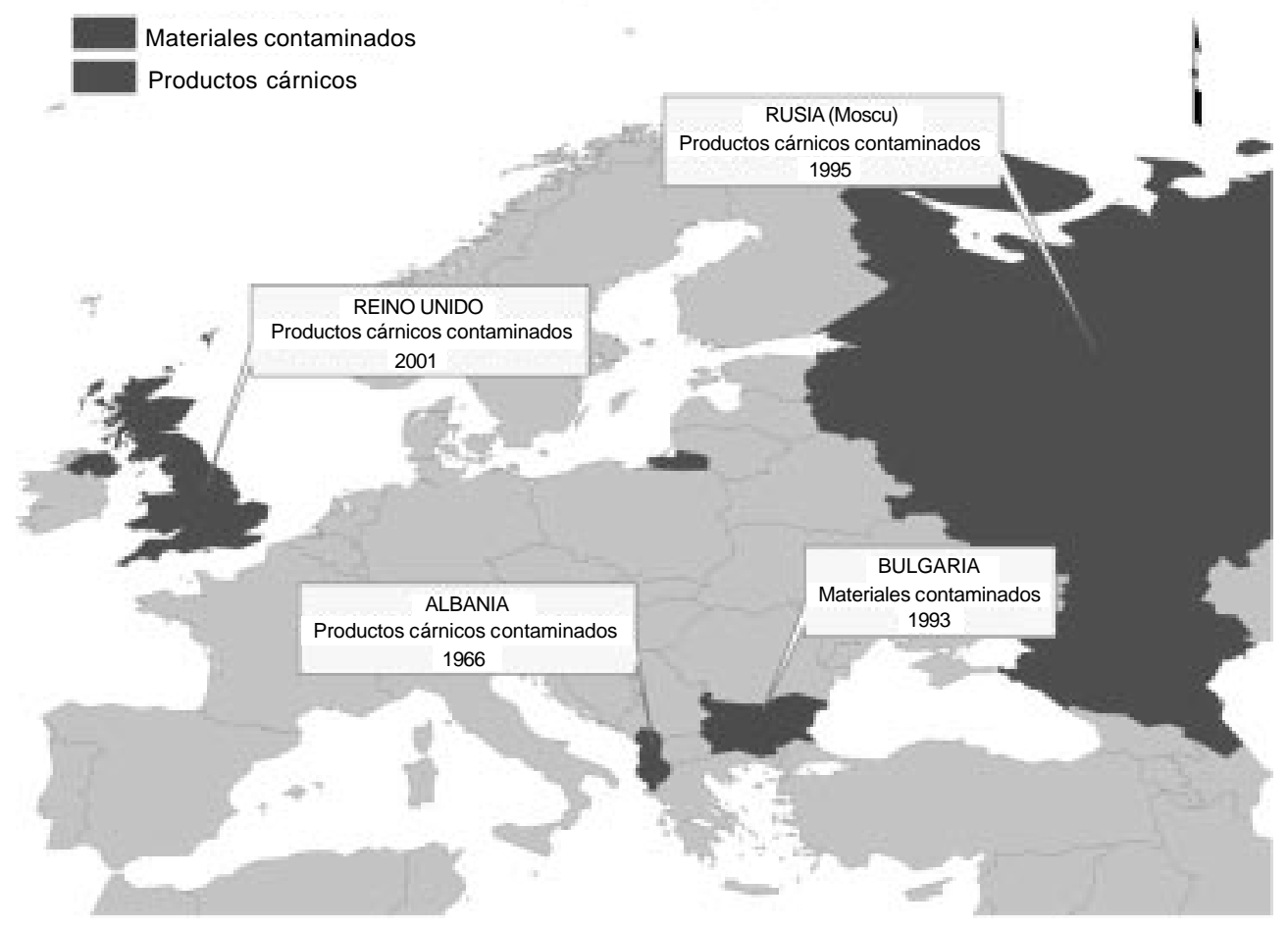

Figura 1. Principales epidemias de fiebre aftosa en Europa (1991-2005) debido a la introducción de productos animales o materiales contaminados. (Main foot and mouth disease epidemics in Europe (1991-2005) caused by the introduction of contaminated products). 
tente sobre la FA limita la independencia de los gobiernos nacionales o locales en la aplicación de medidas de control distintas a las establecidas por organismos internacionales.

En Europa, el control de la fiebre aftosa está fuertemente influenciado por las directrices establecidas por la Unión Europea (UE) que prohiben, por ejemplo, la vacunación profiláctica contra la FA desde 1991 en los estados miembros de la Unión. La legislación de la UE, además de afectar a los países miembros también influye sobre el resto de países europeos ya que condiciona su comercio con la UE. Desde 1991, la FA ha afectado Europa en distintas ocasiones, todas ellas controladas mediante sacrificio, o combinando sacrificio y diversas estrategias de vacunación (Leforban y Gerbier, 2002 y Valarcher et al., 2008). Los esfuerzos de los países libres de la enfermedad se centran en evitar la introducción del virus de la FA impidiendo la importación de animales y productos de origen animal desde países afectados. Sin embargo, las epidemias de los últimos años demuestran que es imposible el control absoluto de las vías de introducción. Esta revisión bibliográfica repasa los brotes de fiebre aftosa en el Continente Europeo de 1991 a 2005. Las epidemias han sido agrupadas según la vía de entrada del virus, siendo la introducción de productos contaminados y animales infectados los principales grupos.

Posteriormente a 2005, sólo tenemos constancia de un nuevo brote de enfermedad en Europa, que se confirmó el día 3 de agosto del 2007 en una granja en Surrey, Reino Unido. Investigaciones posteriores establecieron que el origen más probable fue una fuga de virus de la FA desde un laboratorio de investigación situado a $4 \mathrm{~km}$ de la primera granja afectada (Spratt, 2007). Si bien este brote fue controlado rápidamente por las autoridades inglesas, el origen de la epidemia recuerda la situación en Europa a mediados de los años 80 cuando diversas epidemias causadas por el escape de virus desde laboratorios (Alemania en 1987) o el uso inapropiado de vacunas inactivadas (Italia en 1985-86) propiciaron que a principios de los años 90 se prohibiese la vacunación para el control de la fiebre aftosa en Europa (Valarcher et al., 2008).

\section{EPIDEMIAS FA EN EUROPA 1991-2005}

\section{INTRODUCCIÓN DE PRODUCTOS CONTAMI- NADOS}

\section{Carne y productos cárnicos}

El virus de la fiebre aftosa puede sobrevivir en carne y productos cárnicos un tiempo altamente variable dependiendo del tipo de producto y el procesado al que se someta. Así, el tiempo de supervivencia en carne con hueso es mucho mayor que en carne deshuesada (DEFRA, 2004 y Cottral, 1969). La refrigeración y la congelación aumentan los tiempos de supervivencia, que oscilan entre 2 y 196 días para carne refrigerada deshuesada y con hueso respectivamente (Pharo, 2002 y Hyslop, 1970) y llega a los 224 días en canales congeladas (Hyslop, 1973). El virus es también capaz de sobrevivir durante largos periodos (190 días) en productos curados (Dhennin et al., 1980 y Mebus et al., 1993). Por lo tanto los productos de origen animal contaminados con el virus son una de las posibles vías de introducción.

En Europa, desde 1991 se han producido al menos tres epidemias de FA debido a productos de origen animal contaminados (figura 1). La primera de ellas se produjo en 1995 en Rusia donde se diagnosticó un brote de fiebre aftosa en una granja de 5.800 cerdos en la región de Moscú. El foco se controló rápidamente sacrificando los animales de la granja afectada, restringiendo el movimiento de animales y por vacunación en círculo. La cepa responsable del brote estaba relacionada con una cepa previamente aislada en Hong Kong y considerada 
endémica en China. Se supone que el virus entró al importar productos de origen animal desde China, que fueron procesados en un matadero cercano a la granja afectada (Kitching, 1998; Leforban y Gerbier, 2002).

La segunda fue en 1996 cuando se confirmó un brote en el distrito de Korca en el sureste de Albania (figura 1). Se vieron afectados diez pueblos y 284 granjas con un total de 944 vacas, 683 ovejas y cabras y 220 cerdos. Los animales que mostraron signos clínicos fueron sacrificados. Se usó la vacunación en círculo para evitar el avance de la enfermedad. Probablemente la entrada del virus se produjo por la importación de carne infectada procedente del Oriente Medio o la India como indican los estudios moleculares. Este nexo viene reforzado por la constancia de importaciones por parte de Albania de carne de búfalo y oveja de la India y Arabia Saudita respectivamente.

La última ocurrió en el Reino Unido en el 2001 y representó la peor epidemia de fiebre aftosa en un país occidental en los últimos
50 años. La epidemia se cebó especialmente con el Reino Unido pero afectó también a Francia, Holanda e Irlanda. Sólo en el Reino Unido se sacrificaron casi 6 millones de animales debido la epidemia, y ésta tuvo un coste aproximado de 12 mil millones de euros (Kao, 2003).

El primer caso de fiebre aftosa en el Reino Unido fue diagnosticado el 19 de febrero en un grupo de cerdos en un matadero de la zona de Essex. Investigaciones posteriores relacionaron el brote con una granja de engorde de cerdos que usaba restos de comida para alimentar a los animales. La epidemia fue probablemente debida a la introducción de forma ilegal de productos infectados con el virus de la FA que posteriormente fueron usados como alimento en la granja en cuestión (Scudamore, 2002). La cepa responsable del brote fue la O o cepa Pan-Asia (Knowles et al., 2001), situándose de nuevo el origen del virus en Oriente Medio. Se presume que la enfermedad estaba presente en la granja de cerdos

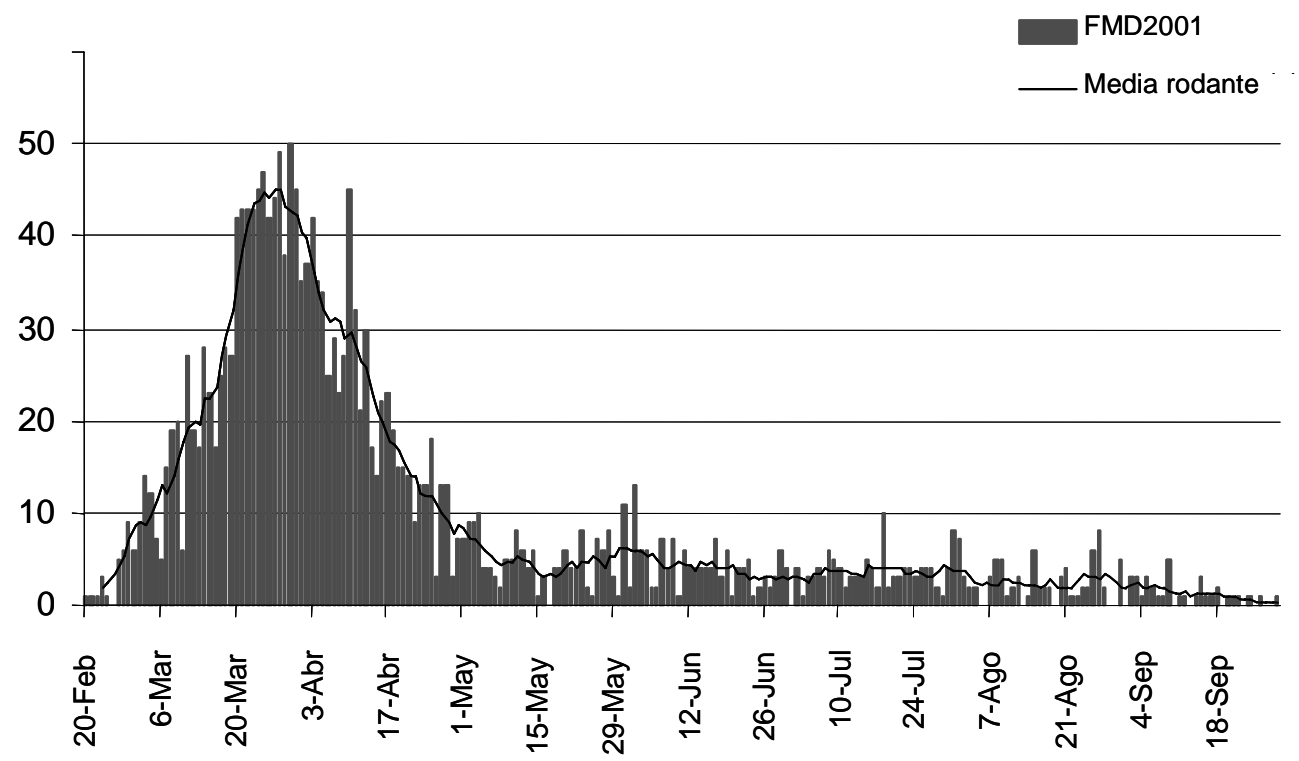

Figura 2. Curva epidémica de la fiebre aftosa en Gran Bretaña en 2001. (The foot and mouth disease epidemic curve in the United Kingdom, 2001). 
desde principios del mes de febrero y que a partir de ella, el virus se diseminó por movimiento de animales infectados al matadero y transmisión aerógena a granjas de ovejas próximas. La infección temprana de ovejas demostró posteriormente ser una de las causas de la gran dispersión de la enfermedad(Gibbens y Wilesmith, 2002, Scudamore, 2002, Alexandersen et al., 2003, Gloster et al., 2003). El 20 de febrero se confirmó la presencia del virus de FA y se establecieron medidas de control consistentes en el sacrificio de los animales afectados y el rastreo y sacrificio de los contactos peligrosos. El 23 de febrero, después de la declaración de diversos nuevos brotes, se restringieron los movimientos de animales en toda Gran Bretaña. Sin embargo, se cree que 119 granjas ya estaban infectadas en distintas zonas del país cuando entraron en vigor estas restricciones (Gibbens y Wilesmith, 2002).

Las medidas de control que se aplicaron durante la epidemia variaron con el tiempo y la región y fueron una fuente importante de debate (Taylor et al., 2004). El sacrificio de granjas infectadas (GI) y de contactos de riesgo (CR) acompañado por la adopción de medidas de bioseguridad fue seguida por políticas de control más drásticas. A partir 15 de marzo se empezaron a sacrificar los animales susceptibles en un radio de $3 \mathrm{~km}$ alrededor de las granjas infectadas. El sacrificio sistemático de granjas contiguas se fue abandonando gradualmente a partir del 26 de abril (Gibbens et al., 2001). El uso de la vacunación como método de control fue planteado, pero finalmente no se puso en práctica (Keeling et al., 2001, Anderson, 2002).

Después de 32 semanas de epidemia (ver la curva epidémica en la figura 2), el 30 septiembre 2001 se declaró el último brote de fiebre aftosa en el país, pero no fue hasta el 22 de enero del 2002 cuando el Reino Unido recuperó su estatus de país libre de fiebre aftosa y hasta el 5 de febrero del mismo año no se levantaron todas las res- tricciones comerciales.

\section{INTRODUCCIÓN DE MATERIALES CONTAMI-} NADOS CON LA FA

El virus de la FA también puede sobrevivir en excreciones y secreciones procedentes de animales infectados y en objetos inanimados contaminados a partir de éstas (Bartley et al., 2002). El tiempo medio de supervivencia depende de la temperatura ambiente y oscila entre una y ocho semanas (McColl et al., 1995 y Podrezova, 1969).

Esta vía de transmisión es importante para la diseminación de la enfermedad una vez la epidemia esta establecida (Maragon et al., 1994), pero es una vía poco frecuente en la introducción de la enfermedad en zonas libres. Sin embargo este es el origen atribuido a una epidemia de FA ocurrida en 1993 en Bulgaria (en la región de Khaskovo en el sudeste del país), cerca de las principales vías de comunicación entre Turquía y Europa (figura 1). El brote tuvo lugar en una explotación de 210 vacas de leche que fueron inmediatamente sacrificadas. Las investigaciones epidemiológicas no pudieron determinar conexión alguna entre la granja y animales o productos de origen animal turcos. Se especuló con la posibilidad de un contacto indirecto por material contaminado proveniente de Turquía, ya que en las proximidades de la granja había un hotel donde paraban habitualmente camiones procedentes de este país. El brote se controló sacrificando un total de 510 vacas, 1516 ovejas y cabras y 17 cerdos, y vacunando los animales en la zona próxima a la granja afectada (Kitching, 1998; Leforban y Gerbier, 2002).

\section{INTRODUCCIÓN DE ANIMALES INFECTADOS}

El contacto directo entre animales es el mecanismo más común de transmisión del virus de la fiebre aftosa. El periodo de incubación, que varia con los serotipos y las especies, combinado con la alta infectividad, dificulta el control de esta vía (Alexandersen y Zhang, 2003). El contacto entre animales infectados y susceptibles se 
puede producir por entrada incontrolada de animales, ya sea de forma organizada (comercio ilegal) o por proximidad geográfica, hechos que no son siempre fáciles de discernir. También el comercio legal supone un riesgo y ha sido al origen de algunos brotes de FA en Europa en los últimos años.

\section{COMERCIO ILEGAL}

En 1993 Italia (figura 3) se vio afectada por una epidemia de FA. Se notificaron un total de 57 brotes, 53 en el sur y 4 en el norte del país. Un grupo de vacas con certificados de exportación de Croacia fue importado para ser sacrificado en un matadero en Potenza, en el sur de Italia. Estos animales se mezclaron con terneras que posteriormente fueron llevadas a una granja de engorde. El veterinario de esta explotación detectó animales con lesiones vesiculares compatibles con FA, lo notificó a las autoridades veterinarias locales pero continuó su ronda de visitas. La granja fue puesta bajo vigilancia y restricción de movimientos hasta la obtención de los resultados del laboratorio, pero no se tomó ninguna otra medida. Cuando 6 días más tarde, el virus de FA fue finalmente identificado, ya habían sido notificados una serie de brotes en las granjas próximas al primer foco incluyendo granjas visitadas por el veterinario que elevó la primera sospecha de la enfermedad.

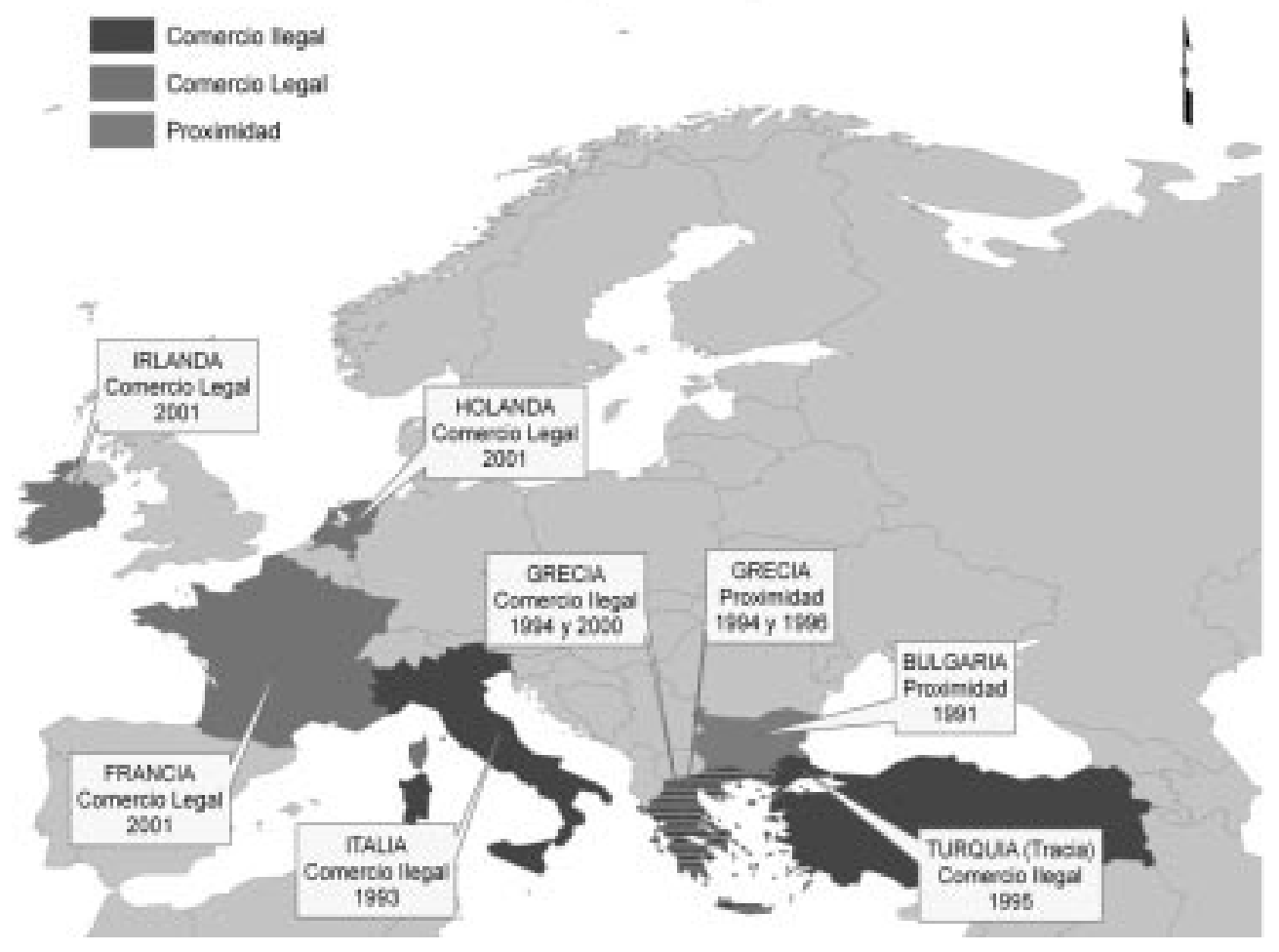

Figura 3. Principales epidemias de fiebre aftosa en Europa (1991-2005) debido a la introducción de animales infectados. (Main foot and mouth disease epidemics in Europe (19912005) caused by the introduction of infected animals). 
Durante los meses siguientes se detectaron varios focos. En total, se sacrificaron más de 8000 vacas, ovejas, cabras y búfalos. Las investigaciones posteriores determinaron que la principal vía de diseminación del virus fue el movimiento de animales infectados. Los certificados de exportación croatas se revelaron falsos y el verdadero origen de los animales era probablemente Checoslovaquia, si bien, este país se presuponía libre de FA. Los estudios moleculares demostraron que la cepa responsable del brote estaba relacionada con una cepa localizada en zonas endémicas del Oriente Medio (Arabia Saudita, Jordania, Israel y Líbano). Aunque no se llegó a demostrar, lo más probable es que las vacas checas fueran mezcladas en Yugoslavia con ganado importado de forma ilegal de Oriente Medio durante la guerra de los Balcanes (Maragon et al., 1994; Kitching 1998).

A finales de Julio de 1994 se declaró un brote de FA en la Prefectura de Xanthi en Grecia (figura 3), aunque posteriormente se determinaría que el brote primario se había originado en la Isla de Lesbos, situada cerca de Turquía. En un principio afectó a 32 granjas de vacuno y ovino. Posteriormente, el transporte de ovejas desde Lesbos extendió la epidemia a las prefecturas de Rodopi y Chalkikiki, En total se identificaron noventa y cinco explotaciones afectadas. El virus causante de este brote era del serotipo $\mathrm{O}$, relacionado con los serotipos circulantes en Turquía y Oriente Medio. Se considera que la vía más probable de introducción del virus en la isla de Lesbos fue la importación ilegal de ovejas de Turquía para poder solicitar los subsidios a la UE (Kitching, 1998; Leforban y Gerbier, 2002).

Un brote de FA detectado en 1995 en la región turca de Tracia tuvo continuidad en 1996 con la confirmación en mayo y junio de dos brotes del serotipo O (figura 3). Estos brotes se asociaron con el movimiento de ganado vacuno a mercados y la posterior devolución ilegal de los animales a las granjas, debido al descenso de los precios de la carne de vacuno provocada por la irrupción de la encefalopatía espongiforme bovina. Antes de ser devueltos a las granjas, los animales fueron mezclados en el mercado con otras vacas, alguna de las cuales, probablemente, estaba infectada. Los brotes fueron controlados mediante el sacrificio de las vacas afectadas (16 en total), desinfección, control de movimientos y vacunación en círculo (Kitching, 1998; Leforban et al., 2002).

Seis años después, Grecia volvió a sufrir un brote de fiebre aftosa (figura 3). El día 10 de julio del 2000 se detectaron los dos primeros casos compatibles con la enfermedad en Evros, cerca de la frontera greco turca. El día 11 de julio se confirmó la enfermedad y basándose en la antigüedad de las lesiones, se determinó el 2 de julio como el día más probable de introducción del virus. En total en julio resultaron infectadas 6 granjas y en agosto 3 más. La cepa responsable de este brote fue Asia 1, cepa detectada con anterioridad en Irán (1999) y Turquía (1999 y 2000). La vía de entrada de esta cepa fue probablemente a través del movimiento de animales vivos entre Pakistán, Irán, Turquía y finalmente Grecia. El brote se controló mediante sacrificio de los animales infectados y sospechosos (5 400 vacas, 2300 ovejas y cabras y 300 cerdos) sin necesidad de vacunar (Leforban y Gerbier, 2002).

\section{Proximidad geOgráfICA}

Las fronteras entre países no son siempre tan impermeables al tránsito de animales como se supone. Especialmente en zonas donde la producción animal es importante y las poblaciones a ambos lados de la frontera comparten fuertes lazos étnicos y/o culturales.

En 1991 se produjo un caso curioso cuando se notificó un brote de fiebre aftosa en el distrito de Yambol en Bulgaria (figura 3), aproximadamente $15 \mathrm{~km}$ al norte de la frontera con Turquía. Se detectaron signos clínicos de FA en un grupo de 99 bovinos que permanecían estabulados en un área 
forestal cerca de un rebaño de 400 ovejas. Se sacrificaron y destruyeron todos los animales susceptibles de la granja y se vacunaron un total de 44895 vacas y 6547 ovejas de la zona. Los análisis moleculares mostraron que el virus responsable de esta epidemia pertenecía al serotipo $\mathrm{O}$, que estaba presente en la Turquía asiática. La proximidad con la frontera turca sugería que el origen se situaba en ese país. Sin embargo, las pruebas serológicas realizadas en animales domésticos y fauna salvaje susceptible (ciervos y jabalíes) de la zona del brote resultaron negativas. Tampoco se encontró ninguna relación familiar entre la gente del pueblo afectado y la vecina Turquía; el pueblo estaba situado a una distancia considerable de las principales vías de comunicación entre Turquía y Europa y no se encontraron indicios de la presencia de personas extranjeras en el área durante el periodo crítico. La explicación más plausible de la aparición del brote no se determinó hasta pasados 3 años. Al parecer el origen del foco se debió a disputas entre poblados búlgaros y turcos. Una cabra turca había sido sustraída por los búlgaros, en respuesta a un acto similar por parte de los turcos; la cabra fue escondida posteriormente en el bosque donde se inició el brote y habría sido la causante de la epidemia (Kitching, 1998; Leforban y Gerbier, 2002).

En 1994 y paralelamente a los brotes de FA en la isla griega de Lesbos, se detectaron 5 brotes en la prefectura de Evros en el mismo país, cerca de la frontera con la región de Tracia (Turquía). Estos brotes se debieron probablemente al contacto entre animales turcos y griegos cuando el río Evros - que separa los dos países - presentaba un bajo caudal que permitía el paso de los animales. Durante la epidemia se sacrificaron 1241 vacas, 12450 ovejas, 4738 cabras, 139 cerdos y 5 ciervos, y no se uso la vacunación como medida de control (Kitching, 1998; Leforban y Gerbier, 2002).

Los brotes de FA se repitieron de nuevo en 1996 en Evros, el primero de una serie de
39 brotes de FA del mismo serotipo O. Todos los brotes se concentraron en 3 zonas. El primer grupo de tres brotes se localizó en la zona sureste de Evros y su origen fue atribuido a la importación ilegal de ovejas por parte de granjeros con lazos familiares en Turquía. Las otras dos zonas afectadas estaban situadas cerca del río Evros. Al igual que en el brote de 1994, el origen de la enfermedad se debió al contacto entre animales de los dos países cuando el nivel del río bajó lo suficiente para permitir el paso de los animales. Se sacrificaron unos 1800 vacas, 5000 pequeños rumiantes y 30 cerdos (Kitching, 1998; Leforban y Gerbier, 2002).

\section{Comerciolegal}

Tres países europeos (República de Irlanda, Francia y Holanda) se vieron también afectados por brotes de FA durante el año 2001 (figura 3). En los 3 casos se determinaron nexos epidemiológicos y moleculares con el brote en el Reino Unido y la transmisión se produjo por el comercio legal de animales infectados.

Francia registró 2 focos de FA en su territorio, el 13 y el 23 de marzo del 2001. En ambos casos los focos estaban relacionados con ovejas importadas del Reino Unido. Cuando se declaró el brote del Reino Unido el día 20 de febrero, se pusieron en marcha los planes para evitar la entrada de animales desde este país e identificar animales ya en territorio francés, que podrían estar contagiados con el virus de la FA. Se identificaron un total de 31477 ovejas, que posteriormente se sacrificaron junto con los animales susceptibles que estaban o habían estado en contacto con ellas (en total 57968 animales). A pesar de estas medidas de prevención se registraron dos brotes de FA. El primer brote afectó una granja de vacuno de leche situada a 500 metros de una explotación de ovejas que había importado animales de una granja infectada en el Reino Unido, poco antes de la prohibición de movimiento de animales. El segundo brote se detectó el día 23 de marzo en una granja 
que había adquirido animales de una explotación afectada. La epidemia se controló mediante el sacrificio de animales afectados y el sacrificio preventivo. También se pusieron en marcha medidas de vigilancia con un total de 17932 pruebas serológicas realizadas, siendo todas negativas excepto los dos brotes localizados y siete grupos de ovejas importadas desde el Reino Unido (Chmitelin y Moutou, 2002).

En la República de Irlanda se afectó una sola granja, el foco se declaró el 22 de marzo en una granja situada a $9 \mathrm{~km}$ del primer caso en Irlanda del Norte, y si bien no se pudieron establecer vínculos formales, se considera probable que esta fuera el origen de la infec- ción. El diagnóstico se basó en signos clínicos y resultados de laboratorio. La antigüedad de las lesiones permitió establecer la fecha de infección entre el 25 de febrero y el 6 de marzo. Las medidas de control adoptadas fueron el sacrificio de las especies susceptibles a la FA en un radio de $1 \mathrm{~km}$ Se sacrificaron un total de 1029 vacas (46 granjas), 47958 ovejas (260 granjas), 98 cabras, 282 ciervos y 70 cerdos, también se sacrificaron un total de 238 cabras salvajes. La rápida detección y adopción de las medidas de control evitaron la dispersión de la enfermedad (Griffin y O'Reilly, 2003).

Holanda fue otro de los países afectados por el brote de fiebre aftosa durante el

Tabla I. Principales brotes de fiebre aftosa por país ocurridos en la Europa entre 1991 y 2004. (Main foot and mouth disease epidemics in Europe between 1991 and 2004).

\begin{tabular}{|c|c|c|c|c|c|c|c|c|}
\hline \multirow[b]{2}{*}{ Año } & \multirow[b]{2}{*}{ País } & \multirow[b]{2}{*}{ Serotipo } & \multirow[b]{2}{*}{ Bovino } & \multicolumn{3}{|c|}{ Sacrificados } & \multirow[b]{2}{*}{ Ciervos } & \multirow{2}{*}{$\begin{array}{l}\text { Sistema } \\
\text { de control }\end{array}$} \\
\hline & & & & Ovino & Caprino & Suidos & & \\
\hline 1991 & Bulgaria & $\mathrm{O}$ & 99 & 400 & & & & $S+V$ \\
\hline \multirow[t]{2}{*}{1993} & Bulgaria & $\mathrm{O}$ & 510 & 1516 & 17 & & & $S+V$ \\
\hline & Italia & $\mathrm{O}$ & 8000 & & & & & $S$ \\
\hline 1994 & Grecia & $\mathrm{O}$ & 1241 & 12450 & 4738 & 139 & 5 & $S$ \\
\hline \multirow[t]{2}{*}{1995} & Rusia & $\mathrm{O}$ & & & & 5800 & & $S+V$ \\
\hline & Turquía (Tracia) & $\mathrm{O}$ & 6 & & & & & $S+V$ \\
\hline \multirow[t]{6}{*}{1996} & Turquía (Tracia) & $\mathrm{O}$ & 16 & & & & & $S+V$ \\
\hline & Grecia & $\mathrm{O}$ & 1800 & 5000 & 30 & & & $\mathrm{~S}$ \\
\hline & Bulgaria & $\mathrm{O}$ & 47 & 7 & 11 & & & $\mathrm{~S}$ \\
\hline & Albania & A & 463 & 74 & 86 & & & $S+V$ \\
\hline & Macedonia & A & 4363 & & & & & $S+V$ \\
\hline & Kosovo & $?$ & 2298 & 734 & 496 & & & S \\
\hline \multirow[t]{3}{*}{2000} & Grecia & Asia 1 & 5400 & 2300 & 300 & & & $S$ \\
\hline & Turquía & O/A/Asia 1 & & & & & & \\
\hline & Rusia & $\mathrm{O}$ & & & & & & \\
\hline \multirow[t]{5}{*}{2001} & Reino Unido & $\mathrm{O}$ & 6000000 & & & & & $S$ \\
\hline & Francia & 0 & 57968 & & & & & S \\
\hline & República de Irlanda & $\mathrm{O}$ & 1029 & 47958 & 98 & 70 & 282 & S \\
\hline & Holanda & $\mathrm{O}$ & 260000 & & & & & $S^{*}$ \\
\hline & Turquía & O/A/Asia 1 & & & & & & \\
\hline 2002 & Turquía (Anatolia) & O/A/Asia 1 & & & & & & \\
\hline 2003 & Turquía (Anatolia) & $\mathrm{A} / \mathrm{O}$ & & & & & & \\
\hline \multirow[t]{2}{*}{2004} & Turquía (Anatolia) & $\mathrm{A} / \mathrm{O}$ & & & & & & \\
\hline & Rusia (Asia) & $?$ & & & & & & \\
\hline
\end{tabular}


año 2001. A pesar de la prohibición de importar animales desde el Reino Unido, el día 24 de Febrero el virus de FA fue introducido en Holanda, lo más probable a través de terneros irlandeses contaminados a su paso por Francia. Cuando se declaró el primer caso se calcula que entre 6 y 10 granjas ya estaban infectadas. La transmisión por movimientos de personas (especialmente veterinarios y granjeros) fue una de las vías más importantes de dispersión. Una vez se detectó el primer brote en marzo, impusieron la prohibición de todo movimiento animal durante 72 horas, seguido por las medidas de control establecidas por la UE: (1) sacrificio de granjas infectadas, (2) aplicación de medidas de bioseguridad, (3) establecimiento de áreas de protección y de vigilancia y (4) estudios epidemiológicos para determinar el origen de la enfermedad e identificar los animales que tuvieron contacto (directo $\mathrm{o}$ indirecto) con las granjas afectadas. Se realizó también el sacrificio preventivo de todos los animales susceptibles en un área de $1 \mathrm{~km}$ de radio alrededor de un foco y de todos los animales en contacto con alguno de los focos confirmados de FA. Rápidamente el número de animales a sacrificar sobrepasó la capacidad operativa de la administración holandesa, y para poder manejar la epidemia se optó por la vacunación de los animales susceptibles en las zonas próximas a los brotes para después sacrificarlos; esta medida afectó a 177474 animales. El último foco se detectó el 22 de abril y el resultado final de la epidemia de FA en Holanda se cobró 260000 animales con un total de 26 focos (Bouma et al., 2003).

\section{CONCLUSIÓN}

A modo de resumen, la tabla I presenta las características más destacadas de los principales brotes de fiebre aftosa ocurridos en Europa entre 1991 y 2005. El año que registró el mayor número de brotes fue 1996, en que 9 países declararon la enfermedad en su territorio. El serotipo O, originario de
Asia y Oriente Medio, fue el que apareció con más frecuencia, aunque los serotipos A y Asia 1 también fueron detectados de forma esporádica en 1996 y en el 2000 indicando el probable origen de los brotes.

El modo de entrada del virus en zonas libres fue variado pero prevaleció como principal vía el movimiento de animales vivos desde países con FA (figura 3) ya que estuvo asociado a los brotes de Bulgaria (1991, 1993 y 1996), Italia (1993), Grecia (1994, 1996 y 2000) y Francia, Holanda y República de Irlanda en el 2001, en algunas ocasiones debido al comercio ilegal y en otras debido al contacto fortuito de animales en la frontera turca. Si bien el contagio por contacto indirecto no fue la vía de entrada más común en los brotes europeos, si que fue responsable de la mayor epidemia de todas, la del Reino Unido en el 2001. Por tanto, todas las posibles vías de contagio deben considerarse en la planificación de los sistemas de control y lucha, incluso la transmisión aérea, que si bien no tuvo importancia entre 1991 y el 2005, si que jugó un papel relevante en la epidemia del Reino Unido en 1966-67.

Europa no es homogénea, ni política ni geográficamente y ha evolucionado de forma considerable entre 1991 y el 2005. En teoría, y así lo expresan los expertos (Leforban y Gerbier, 2002), el riesgo de introducción del virus de FA es heterogéneo y por ello no se puede interpretar de la misma forma un brote en la frontera turca y una epidemia en el centro de la UE. La paradoja es que en los últimos años zonas con, en teoría, un mayor riesgo de sufrir un brote de FA como la Península Ibérica se han mantenido libres la enfermedad, pero países geográficamente aislados como el Reino Unido han sido afectados de forma repetida (2001 y 2007).

Si bien la gran epidemia del 2001 propició el debate sobre los métodos de control disponibles para evitar la entrada del virus de la FA así como para erradicar la enfermedad en caso de entrada en Europa, los cam- 
bios introducidos en la legislación no han variado demasiado la forma de gestionar las epidemias desde 1991. Es por ello que en Europa los brotes de FA fueron controlados de forma similar; de hecho Bulgaria, en 1993, fue el único país que usó la vacunación combinada con el sacrificio para controlar la epidemia de FA, en el resto de ocasiones se usó el stamping out (sacrificio en masa) como método de lucha, si bien hay que recordar que en el 2001 Holanda usó la vacunación como método de contención antes de proceder al sacrificio.

El coste final de un brote de FA es complicado de determinar y viene determinado por los costes directamente asociados a la enfermedad y su control (animales sacrificados y vacunados, estudios serológicos, logística y personal), los costes indirectos (restricciones comerciales) y demás costes sociales. Las cifras de animales sacrificados y/o vacunados pueden usarse para evaluar el coste de cada brote de forma aproximada. Entre 1991 y el 2005 el número de animales sacrificados y por tanto la importancia de los brotes, varió de forma importante entre países, los valores oscilaron entre los 70

\section{BIBLIOGRAFÍA}

Alexandersen, S., R. Kitching, L. Mnasley and A. Donaldson. 2003. Clinical and laboratory investigations of five outbreaks of foot-andmouth disease during the 2001 epidemic in the United Kingdom. Vet. Rec., 152: 489-496.

Alexandersen, S., Z. Zhang, I. Donaldson and J.M. Garland. 2003. The pathogenesis and diagnosis of foot-and-mouth disease. J. Comp. Path., 129: 1-36.

Anderson, I. 2002. Foot and mouth disease 2001: Lessons to be learned inquiry. HC Paper 888 . The Stationary Office. London.

Bartley, L.M., C.A. Donnelly and R.M. Anderson. 2002. Review of foot-and-mouth disease virus survival in animal excretions and on fomites. Vet. Rec., 151: 667-669.

Bouma A, A.R.W. Elbers, A. Dekker, A. de Koeijer, C. Bartels, P. Vellena, P. van der Wal, E.M.A. van Rooij, F.H. Pluimers and M.C.M. de Jong. 2003. animales sacrificados en Bulgaria en 1996 a los 6 millones sacrificados en el Reino Unido en el 2001. Eliminando estos extremos, el número medio de animales sacrificados en un país de la UE debido a un brote de FA se sitúa en unos 60000 animales.

En definitiva, los brotes de FA en Europa en los últimos años, pero especialmente la epidemia del 2001 , ponen de manifiesto el riesgo que esta enfermedad representa para países libres de la FA, y las dificultades para controlar la enfermedad una vez se ha establecido. El 2001 fue sin duda un punto de inflexión y tuvo como resultado la revisión de los planes de contingencia en los países Europeos. Las nuevas medidas establecidas parece que tuvieron un cierto impacto ya que entre el 2001 y 2005 no se produjeron brotes en Europa central, los más cercanos se presentaron en Georgia (dos brotes en el 2002), en Rusia (un brote en 2004-2005 cerca de la frontera con China) y en Turquía (epidemias de forma regular en Anatolia). Pero estos casos, junto con el brote del Reino Unido en el 2007 debido a la fuga del virus desde un laboratorio, ponen en evidencia que el riesgo sigue siendo importante.

The foot-and-mouth disease epidemic in The Netherlands in 2001. Prev. Vet. Med., 57: 155156.

Chmitelin, I. and F. Moutou. 2002. Foot and mouth disease: lessons to be learned from the experience in France. Rev. Sci. Tech. Off. Int. Epiz., 21: 731-737.

Cottral, G.E. 1969. Persistence of foot and mouth disease virus in animals, their products and the environment. Bull. Off. Int. Epiz., 71: 549-568.

DEFRA. 2004. Assessment of the risk to the livestock population of Great Britain from the illegal importation of meat and meat products (http://www.defra.gov.uk/animalh/illegali/pdf/ risk-assessment04.pdf). Consultado: 23/09/ 2006.

Dhennin, L. , A. Frouin, B. Gicquel, J.P. Bidard et J. Labje.1980. Risque de dissemination du virus aphteux par la charcuterie crue. Bull. Acad. 


\section{PICADO, NAPPY CASAL}

Vet. France, 53: 315-322.

Donaldson, A.I., S. Alexandersen, J.H. Sorensen and T. Mikkelsen. 2001. Relative risks of uncontrollable (airborne) spread of FMD by different species. Vet. Rec., 148: 602-604.

Gibbens, J., C. Sharpe, J. Wilesmith, L. Mansley, E. Michalopoulou, J. Ryan and M. Hudson. 2001. Descriptive epidemiology of the 2001 foot-andmouth disease epidemic in Great Britain: the first five months. Vet. Rec., 149: 729-743.

Gibbens, J.C. and J.W. Wilesmith. 2002. Temporal and geographical distribution of cases of footand-mouth disease during the early weeks of the 2001 epidemic in Great Britain. Vet. Rec., 151: 407-412.

Gloster, J., H.J. Champion, J.H. Sorensen, T. Mikkelsen, D. Ryall, P. Astrup, S. Alexandersen, A. Donaldson. 2003. Airborne transmission of foot-and-mouth disease virus Burnside Farm, Heddon-on-the-Wall, Northumberland, during the 2001 epidemic in the United Kingdom. Vet. Rec., 152: 525-533.

Griffin, J.M. and P.J. O'Reilly. 2003. Epidemiology and control of an outbreak of foot-and-mouth disease in the Republic of Ireland. Vet. Rec., 152: 705-712.

Hyslop, N. 1970. The epizootiology and epidemiology of foot and mouth disease. Adv. Vet. Sci. Comp. Med., 14: 261-307.

Hyslop, N. 1973. Transmission of the virus of foot and mouth disease between animals and man. Bull. Org. Mond. Sante., 49: 577-585.

Kao, R.R. 2001. Landscape fragmentation and foot-and-mouth disease transmission. Vet. Rec., 148: 746-747.

Kao, R.R. 2002. The role of mathematical modelling in the control of the 2001 FMD epidemic in the UK. Trends Microbiol., 10: 279-286.

Kao, R. 2003. The impact of local heterogeneity on the alternative control strategies for foot-andmouth disease. Proc. R. Soc. Lond. B, 270: 2557-2564.

Keeling, M.J., M. Woolhouse, D. Shaw, L. Matthews, M. Chase-Topping, D. Haydon, S.J. Cornell, J. Kappey, J. Wilesmith and B. Grenfell. 2001. Dinamics of the $2001 \mathrm{UK}$ foot and mouth epidemic: Stochastic dispersal in a heterogeneous landscape. Science, 294: 813-817.

Kitching, R.P. 1998. A recent history of foot-andmouth disease. J. Comp. Pathol., 118: 89-108
Knowles, N.J., A.R. Samuel, P.R. Davies, R.J. Midgley and J.F. Valarcher. 2001. Outbreak of foot-and-mouth disease virus serotype $O$ in the UK caused by a pandemic strain. Vet. Rec., 148: 258-259.

Leforban, Y. and G. Gerbier. 2002. Review of the status of foot and mouth disease and approach to control/eradication in Europe and Central Asia. Rev. Sci. Tech. Off. Int. Epiz., 21: 477492.

Maragon, S., E. Facchin, F. Moutou, I. Massirio, G. Vincenzi and G. Davies. 1994. The 1993 Italian foot-and-mouth disease epidemic: epidemiological features of the four outbreaks identified in Verona province (Veneto region). Vet. Rec., 135: 53-57.

McColl, K.A., H.A. Westbury, R.P. Kitching and V.M. Lewis. 1995. The persistence of foot-andmouth disease virus on wool. Austral. Vet. J., 72: 286-292

Mebus, C.A., C. House, F. Ruiz Gonzalvo, J.M. Pineda, J. Tapiador, J.J. Pire, J. Bergada, R.J. Yedloutschnig, S. Sahu, V. Becerra and J.M. Sanchez-Vizcaino. 1993. Survival of foot and mouth disease, African swine fever, and hog cholera viruses in Spanish serrano cured hams and lberian cured hams; shoulders and loins. Food Microbiol., 10: 133-143.

Pharo, H.J. 2002. Foot-and-mouth disease: an assessment of the risks facing New Zealand. New Zeal. Vet. J., 50: 46-55.

Podrezova, E.A. 1969. Viability of foot-and-mouth disease virus in pastures. Veterinariia, 5: 9496.

Radostits, O., C. Gay, D. Blood and K. Hinchcliff. 2000. Veterinary Medicine, 9th ed. W.B. Saunders, London. p. 1059-1069.

Ryan, E., J. Gloster, S.M. Reid, Y. Li, N.P. Ferris, R. Waters, N. Juleff, B. Charleston, B. Bankowski, S. Gubbins, J.W. Wilesmith, D.P. King and D.J. Paton. 2008. Clinical and laboratory investigations of the outbreaks of foot-and-mouth disease in southern England in 2007. Vet Rec., 163: 139-47.

Scudamore, J.M. 2002. Origin of the UK foot and mouth disease epidemic in 2001. Department for Environment, Food and Rural Affairs. UK.

Spratt, B.G. 2007. Independent review of the safety of UK facilities handling foot-and-mouth disease virus. www.defra.gov.uk/animalh/ 


\section{BROTES DE FIEBRE AFTOSA EN EUROPA (1991-2005)}

diseases/fmd/investigations/pdf/spratt_final.pdf. Consultado: 29/08/2008.

Valarcher, J.F., Y. Leforban, M. Rweyemamu, P.L. Roeder, G. Gerbier, D.K. Mackay, K.J. Sumption,
D.J. Paton and N.J. Knowles. 2008. Incursions of foot-and-mouth disease virus into Europe between 1985 and 2006. Transbound Emerg. Dis., 55: 14-34. 